\title{
Developing Swiss Paraplegic Research: Building a research institution from the comprehensive perspective
}

\author{
GEROLD STUCKI ${ }^{1,2,3}$, JAN D. REINHARDT ${ }^{1,4}$, ALARCOS CIEZA $^{1,3}$, MIRJAM BRACH $^{1,2}$, \\ MARCO CELIO $^{1,5}$, DANIEL JOGGI ${ }^{6,7}$, BEAT VILLIGER $^{8}$, GUIDO A. ZÄCH $^{9}$ \& \\ WALTER KRIEG ${ }^{1}$ \\ ${ }^{1}$ Swiss Paraplegic Research, Nottwil, Switzerland, ${ }^{2}$ Department of Physical Medicine and Rehabilitation, Ludwig-Maximilian \\ University, Munich, ${ }^{3}$ ICF Research Branch of the WHO CC FIC (DIMDI), Institute for Health and Rehabilitation Sciences, \\ Ludwig-Maximilian University, Munich, Germany, ${ }^{4}$ Department of Sociology, University of Lucerne, ${ }^{5}$ Faculty of Natural \\ Sciences, University of Fribourg, Switzerland, ${ }^{6}$ Swiss Paraplegic Association, Nottwil, ${ }^{7}$ European Spinal Cord Injury \\ Federation, ${ }^{8}$ Swiss Paraplegic Centre, Nottwil, and ${ }^{9}$ Swiss Paraplegic Foundation, Nottwil, Switzerland
}

\begin{abstract}
Purpose. To illustrate the conceptualization and development of a research institution from the comprehensive perspective based on the integrative model of functioning provided by the World Health Organization's (WHO) International Classification of Functioning, Disability and Health (ICF). The newly founded research institution Swiss Paraplegic Research which focuses on the comprehensive study of spinal cord injury (SCI) serves as an example.

Method. Description of organizational development and structure.

Results. The creation of specialized research institutions which develop their core competence from the comprehensive perspective poses unique challenges. It is depicted how these challenges can be met through several approaches. These encompass the identification and specification of a common mission and research goals, the organization of research along distinct scientific fields, the set-up of a respective core competence, and the design of research structures suited to conduct studies of high methodological and organizational complexity. Finally, they comprise the development of a transdisciplinary workforce and the integration into a research landscape which is organized along scientific disciplines and not along interdisciplinary themes.

Conclusion. The ideas and approaches described in this paper may serve as an example for creating integrative research institutions dedicated to human functioning and rehabilitation research from the comprehensive perspective.
\end{abstract}

Keywords: Human functioning, research institute, rehabilitation, disability, organizational structure, ICF

\section{Introduction}

There is an urgent need to increase research capacity to address the challenges summarized in the World Health Organization's (WHO) resolution on disability, including rehabilitation, management and prevention $[1,2]$. Health conditions, such as spinal cord injury (SCI), can affect almost every area of life from cell function to societal participation [3,4]. Meaningful research must therefore comprehensively address the individual as well as the social needs of people who experience or are likely to experience disability. There is, thus, the specific need for human functioning and rehabilitation research from the comprehensive perspective based on the integrative model of functioning, disability and health $[1,5]$ as provided by WHO's International Classification of Functioning, Disability and Health (ICF) [6].

Human functioning and rehabilitation research from the comprehensive perspective is essential to improve our understanding of functioning and disability, to identify targets for comprehensive interventions and to translate advances in the biomedical sciences and engineering into tangible

Correspondence: Prof. Gerold Stucki, MD, MS, Swiss Paraplegic Research (SPF), 6207 Nottwil, Switzerland. Tel: +41 419396571.

E-mail: gerold.stucki@paranet.ch/gerold.stucki@med.uni-muenchen.de 
benefits for people [1,5,7-9]. Specialized research institutions can promote the development of the necessary research capacity by providing a suitable infrastructure, training researchers and offering attractive career paths. They are instrumental in introducing new themes like human functioning and rehabilitation into the research landscape by fostering educational programs, interdisciplinary university centers and collaboration networks, and by opening new funding channels $[10-12]$.

The development of a research institution committed to human functioning and rehabilitation research from the comprehensive perspective poses unique challenges. These include the identification and specification of a common mission and research goals which serve as a guideline for the set-up of a coherent research agenda and foster a common identity among researchers originally trained in different disciplines. They also embrace the professional organization of research around distinct but related scientific fields $[5,8]$ as well as the development of a respective core competence [13] and of organizational structures and processes suited to conduct studies of high methodological and organizational complexity. Finally, they comprise the development of a transdisciplinary work force and the integration into a research landscape which is organized along scientific disciplines and not along interdisciplinary themes.

The objective of this paper is to illustrate exemplary approaches to address these challenges using the development of Swiss Paraplegic Research (SPF), a newly founded research institution dedicated to the comprehensive study of SCI, as a case in point.

\section{Mission and umbrella goals}

A unifying mission serves to guide the development of a coherent research agenda and functions as a basis for the development of a common identity among researchers. It is pivotal for the amalgamation of researchers with a background in varying scientific disciplines and the integration of research programs across a range of distinct scientific fields and research domains [5,8]. It is also instrumental for the attraction of motivated and talented researchers from related scientific disciplines, to get recognition from the scientific community, and to gain confidence from the general public. Considering the example of the SPF, its mission is to contribute to optimal functioning and social integration, health and quality of life of people with SCI through clinical and community oriented research. It is complementary to the missions of the SPF's partner institutions in the context of the Swiss Paraplegic Foundation and was brought together in collaboration with these organizations (Table I).

The translation of an institute's mission into a coherent research agenda representing a truly comprehensive perspective can be facilitated by the specification of the mission through common or 'umbrella' goals. Umbrella goals serve as points of reference for researchers, e.g., in the specification of primary or secondary study endpoints for clinical and community cohort studies. They are also intended to foster the collaboration of researchers in the development of meaningful research programs. SPF has thus developed the following three interrelated umbrella goals which have been derived from the ICF as well as extensive literature searches on gaps in actual SCI research: Participation, impairment control and health maintenance. The umbrella goals also provide a transparent and meaningful basis for the evaluation of program performance and the monitoring of the institute's development. Since these goals are derived from the etiologically neutral ICF framework they may also serve as guides for research programs in other health conditions.

\section{Participation}

According to WHO's integrative model of functioning, participation represents the social component of functioning and refers to a person's involvement in a life situation [6]. Participation in various social areas such as partnership, family, work, leisure, religion, or politics is essential to personal identity [14]. Conversely, participation restrictions encountered by people with health conditions may importantly contribute to the experience of disability [6]. Participation is also an important aspect of an individual's quality of life and life satisfaction

Table I. Swiss Paraplegic Research (SPF) and its mission in the context of the Swiss Paraplegic Foundation.

- The vision of the Swiss Paraplegic Foundation, founded by Dr Guido A. Zäch in 1975, is to constantly improve care and support, and ultimately health and quality of life of people with spinal cord injury (SCI) through a collaborative network of institutions.

- The mission of the Swiss Paraplegic Association, the Swiss patient association of people living with SCI, is to provide services and lifelong support for people with SCI in the community and to foster solidarity and social exchange.

- The mission of the Swiss Paraplegic Centre, a national rehabilitation centre for SCI, is to provide comprehensive rehabilitation and related care from the acute situation to integration in the community.

- The mission of SPF is to contribute to optimal functioning and social integration, health and quality of life of people with SCI through clinical and community oriented research. 
$[15,16]$. A complete deprivation of valued domains of participation will cut off an individual from important emotional and cognitive resources and may result in adverse health consequences [17-19]. Vice versa, sufficient social participation is a prerequisite for the building of social capital and thus may promote health, e.g., through stress buffering $[17,20]$. However, some forms of participation may also have adverse consequences for health and quality of life, e.g., if high efforts in work are combined with low rewards in terms of remuneration or social esteem [21]. Individual participation is also important to society as a whole $[2,22]$. For example, participation restrictions regarding employment not only lead to losses in tax revenue but also to invaluable losses in creative resources. Thus, participation is a major goal of the rehabilitation strategy [23-26].

\section{Participation in SCI}

There are few studies examining participation restrictions of people with SCI in comparison to general population samples [24,27]. When studied in an SCI population, participation has been treated as both an independent and dependent variable. For example, participation has been assumed to have a positive impact on quality of life and life satisfaction [28-32] and on the number of secondary complications, e.g., pressure sores [33]. However, it can also have negative consequences for the individual. For example, people participating in various areas of social life may be more vulnerable to encountering several environmental barriers such as negative attitudes and discrimination at work $[34,35]$.

When studied as a dependent variable, participation has been seen as affected by injury related aspects such as level and severity, education and age at injury [32,36] and pain [36]. It may also be influenced by psychological factors like health locus of control [27,37] as well as by environmental barriers and facilitators [27,32,34-41]. However, only relatively small amounts of variance can currently be explained.

\section{Need for research}

Therefore, there is the need to better understand the factors that influence participation and the impact of participation on impairment, health and quality of life [29]. Future research should provide reliable information on the directions of causation between variables and account for a longitudinal perspective including the study of adaptations to and modifications of environmental conditions [42]. Moreover, a focus on patterns of and experiences with participation may complement the currently predominant focus on participation restrictions. Most importantly, interventions aiming at the improvement of participation, e.g., through the provision of role models [43], need to be explored [32].

In the context of the SPF, participation is a major study endpoint for all epidemiological and comprehensive intervention research. For example, a current research program of the SPF in cooperation with the Faculty of Human Sciences of the University of Lucerne addresses the relationship of participation and environmental factors.

\section{Impairment control}

Impairments are losses or abnormalities in body function and structure characterized through significant deviations from statistical reference standards established for certain populations [6]. Impairments importantly contribute to the experience of disability, both directly through associated symptoms and indirectly by negatively affecting activities and participation. The control of impaired body functions and associated symptoms is thus a major concern to patients across health conditions. For example pain, consistently present within a wide range of chronic conditions [44,45], may involve activity limitations, participation restrictions and a decline in quality of life [44]. Likewise, the control of impaired sleep function is a major need of patients across various conditions [46].

\section{Impairment control in SCI}

SCI is associated with a great variety of impairments. All body functions below the level of the neurological lesion may be affected. Impairments representing complications often lead to re-hospitalization [47] and may negatively affect life satisfaction in persons with SCI [30]. Both in the short run, e.g., with respect to survival, as well as in the long run, e.g., with respect to quality of life, impairment control is thus of utmost importance to people with SCI. The complexity of impairment control in SCI poses unique challenges. Impairments in SCI are often related to each other, e.g., together with mediating or moderating factors primary impairment may lead to secondary impairment and sometimes perilous situations.

Loss of sensibility in body parts below the lesion, for instance, involves a great risk of developing pressure ulcers negatively affecting overall functioning $[33,48]$. Motor dysfunction can entail spasticity [49] which can be associated with pain, is socially stigmatizing and limits activities of daily living. Musculoskeletal and neuropathic pain is a major problem in people with SCI involving a high consumption of medication with accompanying side 
effects [50] as well as decreased participation and decline in quality of life [30,36]. Likewise, dysfunctions of the autonomous nervous system [51] severely affect bladder, bowel, and sexual function, leading to urinary incontinence, obstipation and erectile dysfunction or loss of the ability to achieve orgasm [52,53]. Even life-threatening situations may occur due to autonomic dysreflexia [54] or severe urinary-tract infections [55]. In addition, dysfunctions of the autonomous nervous system produce dangerous disruptions in the respiratory [56] and cardiovascular systems [57]. These may lead to secondary conditions like respiratory infections [58] or orthostatic hypotension [59].

Secondary impairments in SCI may also be caused by restrictions in activities and participation. For example, reduced physical activity and a lack of a mechanical load on lower extremities cause endocrine and metabolic changes [60]. Patients with SCI are therefore at a high risk for osteoporosis [61,62], obesity and insulin resistance [60], whilst the latter may again increase the risk of cardiac events [63].

\section{Need for research}

Future research may importantly contribute to enhance our understanding of the complexity of these various impairments. Additional investigation is needed to gain comprehensive knowledge regarding interventions which can control impairments in body systems and structures. Comprehensive intervention research should also address the relationship among impairments, activities, participation, personal resources and environmental factors as well as the influence of impairments on quality of life.

Studying the mechanisms that can help to control impairment in SCI can thus serve as a major objective of research programs conducted on behalf of the SPF. A current research program of the SPF in cooperation with the Vrije Universiteit Amsterdam, for example, seeks to understand the control of upper extremity pain due to wheelchair propulsion [64].

\section{Health maintenance}

General health is a major concern to everyone, regardless of a pre-existing health condition. Health maintenance is related to the long term prevention of primary or additional health conditions in terms of comorbidity and secondary complications. It is based on the understanding of biological, psychological, social and further environmental variables contributing not only to pathogenesis, but also to salutogenesis [65]. Physical activity, for example, is assumed to prevent obesity and to promote cardiopulmonary fitness which decreases disease risk and mortality [66]. Occasions for physical activity, however, also depend on contextual factors such as neighbourhood infrastructure [67]. Reducing risks to health and promoting factors to secure health are integral components of health maintenance.

Health maintenance faces specific challenges in people with manifest health conditions. Secondary conditions are more likely to occur, are often perilous and require discrete approaches to prevention which has been traditionally neglected by public health [68] and medicine [69]. In addition, healthmaintaining behavior and health-promoting activities may be more difficult to carry out and be hampered by environmental barriers $[69,70]$. In this context, a long-term goal of health maintenance is to make sure that people with health conditions can live up to the life expectancies of the general population.

\section{Health maintenance in SCI}

Since the mean age at injury is estimated to be about 33 years worldwide [71], many SCI survivors need to be prepared for aging with the condition which further increases the already substantial complexity of SCI $[48,72]$. Life expectancies, are still lower than in the general population. In the United States, for example, there are even hints that 'the gap between life expectancies of persons with SCI who have already survived at least 2 years post-injury and comparable individuals from the general population may have actually increased' [73]. Premature death has been shown to be associated with demographics, level and severity of injury as well as secondary complications and comorbidity like diabetes mellitus and cardiac disease, but also with unhealthy lifestyles like smoking or physical inactivity and participation [74,75]. Particularly the latter factors should be amenable to comprehensive health promotion interventions.

Indeed, there is substantial evidence for the health maintaining effects of physical activity and respective exercise [76,77]. Yet, physical capacity [78] and activity levels [79] are reported to be low in the SCI population. Many people with SCI still face considerable barriers to exercise including e.g., low motivation and inaccessible facilities [80,81]. Exercises often require a substantial amount of time, producing opportunity costs with respect to other valued activities. Thus it is a major challenge to motivate people and to offer innovative, integrative and practicable solutions for the enhancement of health [81].

\section{Need for research}

These and other findings reveal the need for further research dedicated to the understanding of the potentially interrelated factors contributing to the 
health maintenance of people with SCI. In addition, many potential interventions like respiratory muscle training [82] still lack supportive evidence with regard to their efficacy and long-term effectiveness.

Therefore, the SPF fosters research programs aiming at the comprehensive understanding of biomedical, personal and environmental factors predicting health maintenance of people with SCI in the community and over the life-span as well as research programs aiming at the development, dissemination, implementation and evaluation of health maintaining interventions, lifelong monitoring systems and community programs for the retention of health-promoting activities. Current research programs at the SPF, for instance, explore approaches to increase cardiopulmonary fitness [83] and to minimize osteoporosis [62] in people with SCI. These programs are developed in cooperation with the Institute for Human Movement Sciences of the ETH Zurich as well as the Radboud University Medical Centre Nijmegen, and the LudwigMaximilian University of Munich, respectively.

\section{The organization of research around distinct scientific fields and the specification of the institute's core competence}

Against the background of an institute's mission and umbrella goals, research programs and projects may be more specifically organized along distinct scientific fields and research domains of human functioning and rehabilitation research which have been described elsewhere [5,8]. Figure 1 shows a graphical depiction of these five distinct scientific fields as well as short definitions of the fields. In this context, a research institution needs to decide on its core competencies regarding scientific fields and research domains.

\section{Areas of competence}

A single research institution can hardly cover the whole spectrum of conceivable research domains. Any research institution which is willing to prosper and promote scientific excellence in the highly competitive international research environment has to identify, develop and maintain a distinctive core competence. The term core competence has been developed in management science [13]. Translated into research institutions within the area of human functioning and rehabilitation, core competence means the strategic ability to develop an innovative understanding of human functioning and rehabilitation and to create interventions that address people's needs more safely, effectively and efficiently. A core competence of a research institution is manifested through the collective learning of the organization coordinating diverse skills and integrating multiple methodologies with regard to the specific strategic orientation. It is thus difficult to imitate [13].

Arguably, the most important decision for the identification of a core competence in human functioning and rehabilitation research and the development of a respective research agenda is the selection of the scientific perspective [5]. Research may be conducted from the partial perspective based on the biomedical model of disease, or from the comprehensive perspective based on the integrative model of human functioning [5]. The following paragraphs are intended to illustrate the selection of the latter perspective.

\section{Developing the core competence from the comprehensive perspective}

Research from the comprehensive perspective is new and challenging. It is also scarcely represented in the actual scientific landscape. It is thus a promising starting point for the identification of a unique and innovative core competence in the area of human functioning and rehabilitation research.

A research institution dedicated to human functioning and rehabilitation research from the comprehensive perspective which can be called an 'integrative research institution' per definition develops its core competence in the human functioning sciences, integrative rehabilitation sciences and professional rehabilitation sciences (Figure 1) [5,8].

The human functioning sciences represent basic sciences from the comprehensive perspective. They aim to understand all components and determinants of human functioning and disability as described in the ICF framework. Research interests range from body functions to participation and from properties of the person to societal policies and particularly focus on the interplay of different components of functioning and contextual factors.

The integrative rehabilitation sciences build on the knowledge, hypotheses and research questions generated by the human functioning sciences. They are the applied sciences from the comprehensive perspective and thus design, integrate and study respective interventions ranging from products and procedures on the micro-level to policies and laws on the macro-level. Their goal is to optimize the performance of people in interaction with the environment.

The professional rehabilitation sciences integrate knowledge from the basic and applied sciences with primarily practical aims. Since they are rooted in the rehabilitation professions, they study how to provide best care with the goal to enable people experiencing or likely to experience disability to achieve and 
maintain optimal functioning in the interaction with their immediate environment.

The three scientific fields from the comprehensive perspective share a holistic view on functioning and disability which emphasizes the interactions of the different components of functioning and contextual factors. The SPF has decided to develop its core competence in the distinct scientific fields representing the comprehensive perspective and thus to develop an integrative and holistic understanding of SCI and living with the condition. Table II shows current examples as well as planned research programs and projects of the SPF in relation to the distinct scientific fields.

\section{Integration of complementary competence}

A strength of an integrative research institution is its ability to incorporate research from the partial perspective focusing on the biomedical aspects of functioning which represents a complementary competence of utmost importance. While an integrative research institution can not cover all domains in the biomedical rehabilitation sciences and engineering or in the biosciences in rehabilitation (Figure 1), collaborations with biomedical research institutions have the potential to result in mutual benefits.

Integrative researchers may, for example, learn from the biosciences how to model and understand the interactions of body functions and structures with the other components of functioning and against the background of contextual factors, e.g., environmental influence on body functions mediated through gene regulation. Vice versa, integrative research institutions can importantly contribute to the translation of biomedical innovations into meaningful practice. They may, for example, provide important insights for the development of more practical and feasible training methods, or on how to integrate aspects like motivation and compliance.

In collaboration with biomedical research institutions, the SPF thus also develops research programs in selected domains of the biomedical rehabilitation sciences and engineering. It focuses on topics that matter to people living with SCI and are rather underrepresented in the actual research landscape. Therefore, the SPF is currently not developing an own program in sensorimotor recovery which is the focus of most studies in SCI but develops the mentioned programs in cardiopulmonary and musculoskeletal health (Table II).

The SPF also facilitates programs in spinal injury research by providing funding and laboratory facilities to university partners. University partners can therefore conduct selected projects, e.g., on neuro- protection [84], in the laboratories of the SPF. SPF researchers and the specialists of the Swiss Paraplegic clinical centre collaborate with these University partners in the development and implementation of clinical validation and epidemiological outcome studies (Table II).

\section{Designing the research process}

The implementation of research programs and projects across distinct scientific fields and research domains requires studies with a high level of organizational and methodological complexity. Therefore, a centralized and professional study center conducting these studies in close collaboration with different research programs is one of the most important aspects of the research organization. The following paragraphs illustrate these issues and how they are addressed in the context of the SPF.

\section{Studies}

Studies with a high level of organizational complexity encompass epidemiological studies in the clinical and community context as well as embedded experimental studies. Studies with a high level of methodological complexity include meta-analytic approaches involving decision analysis and data modeling. They also embrace studies which model the impact of single and comprehensive interventions on functioning of people with a health condition.

\section{Umbrella studies}

Umbrella study is a term to denote cohort studies designed to integrate research programs across distinct scientific fields and research domains. Umbrella studies imply a highly inter- or even transdisciplinary collaboration of researchers addressing a wide range of questions in relation to the understanding of functioning. The comprehensive study of functioning from the acute hospital to integration in the community and over the life-span as well as with regard to comprehensive interventions on the micro, meso and macro levels $[8,85]$ requires distinct but related umbrella studies.

Clinical umbrella studies examine outcomes in terms of functioning in relation to professional practice and under consideration of condition characteristics, personal resources and the environmental context. Impairments are the aspect of functioning of major interest in the acute context. In the early post-acute context, the focus is on activity. In the transition to the community, the focus becomes the envisioned participation.

Community umbrella studies examine functioning of groups of people with a health condition in 


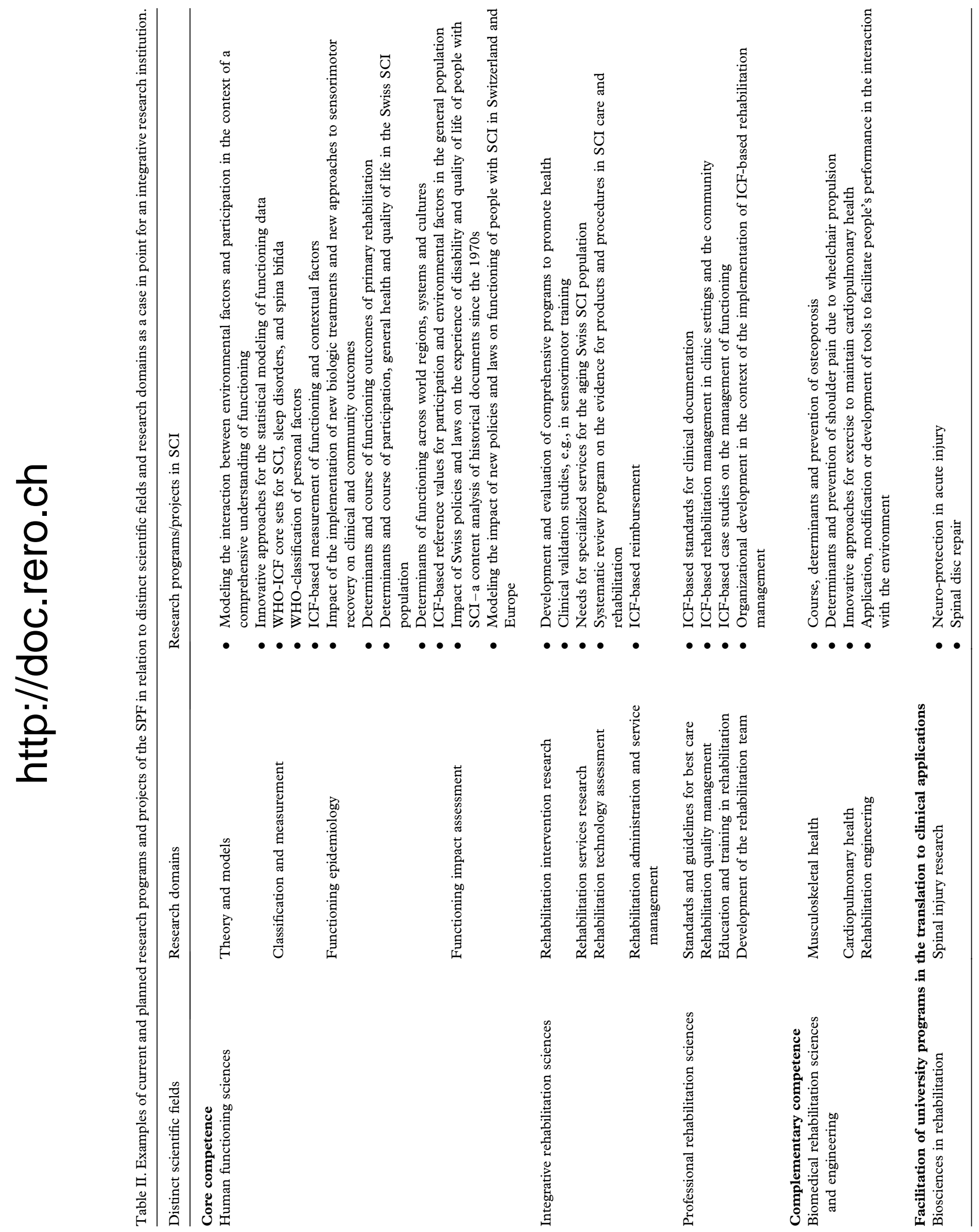


relation to society and particularly with respect to the availability and accessibility of services. Experienced or perceived participation and respective restrictions but also experienced or perceived activity limitations and impairments are aspects of functioning of major interest. Economic outcomes, general health and quality of life are related major study outcomes.

International umbrella studies aim to examine functioning across groups of people with specific health conditions in relation to national and regional policies, laws and economies as well as different cultural beliefs and practices.

Umbrella studies are a unique means to identify problems of people with health conditions experiencing or likely to experience disability as well as targets for respective interventions. They are instrumental in recognizing gaps between 'what is currently done' and 'what could be done' based on available evidence [86]. Although they are non-experimental, umbrella studies are also suitable for evaluating the effectiveness and cost-effectiveness of newly implemented efficacious interventions in real life, the monitoring of their implementation and quality management. They can, therefore, facilitate the continuous evaluation and improvement of professional practice, service provision and payment schemes. They also serve as a basis for policy formulation and the design of programs and projects on the macro-level [8]. Umbrella studies are also highly beneficial for the identification of eligible participants for efficacy or validation studies. This is of utmost importance in health conditions such as SCI where there is only a very limited number of eligible participants making the validation of single and comprehensive interventions a major challenge.

The SPF is developing umbrella studies on all levels. Currently, it conducts an international umbrella study in the context of the development of ICF Core Sets for SCI [3].

\section{Clinical validation studies and comprehensive intervention trials}

Clinical validation studies are essential to find out whether new and efficacious rehabilitation approaches which 'work in principle' also 'work in practice'. They compare different products and procedures, e.g., for sensorimotor training $[87,88]$ in SCI, in order to determine their relative effectiveness and efficiency. Clinical validation studies are thus pivotal in translating the potential of innovative biomedical and engineering interventions into factual benefits for patients and staff.

Comprehensive intervention trials are also crucial within an institution dedicated to the study of human functioning and disability form the comprehensive perspective. They go beyond the study of the effect of single interventions. The term 'comprehensive' highlights the complementarity with the classical intervention research conducted from the biomedical perspective which primarily focuses on the application of determined products and procedures including pharmacological, surgical or behavioral interventions. Comprehensive intervention trials integrate interventions from up to four rehabilitation approaches [24] including approaches to optimize a person's capacity, approaches which build on and strengthen the resources of the person, approaches which provide a facilitating environment and which develop performance in interaction with the environment.

\section{Rehabilitation technology and functioning impact assessment}

Beyond the empirical studies conducted on behalf of a research institution, rehabilitation technology assessment [8] aims at integrating the evidence from a wide range of validation and other studies through systematic reviews and meta-analyses. It then informs all stakeholders about such evidence and provides analyses of the potential safety and costeffectiveness of innovative products and procedures for people with SCI.

Based on knowledge about the effects of current policies and laws on functioning in people with SCI generated in particular through the community and international umbrella studies, human functioning impact assessment [8] can provide policy and decision makers with relevant information on the intended and unintended impact of new policies and laws. Its main focus is on the identification, comparison and modeling of alternatives in policy and law making.

\section{Study center}

To perform studies with a high level of organizational complexity research institutions from the comprehensive perspective may develop a study center which specializes in the conduct of umbrella studies, clinical validation studies and comprehensive intervention trials.

A study center needs to build a core staff with the key competencies to conduct its studies. Its core staff should include an epidemiologist, a statistician, a medical officer, an operation officer, a biometry officer and a writing officer.

The epidemiologist is responsible for the study design and the appropriate selection of relevant study variables and their assessment. The statistician performs the different study specific statistical analyses. The operation officer is responsible for the logistics 
of the umbrella and clinical validation studies as well as comprehensive intervention trials. The medical officer is leading a team of health professionals. $\mathrm{He}$ oversees all interactions with the study participants and is responsible for their health and adherence to ethical standards. The biometry officer accounts for the development of suitable data bases, data management and data analyses. The writing officer supports and coordinates all writing tasks from grant applications to research protocols, publications and implementation materials.

In addition, a study center may operate a consulting service involving researchers of the institution with specific content or methods expertise (see Table III). At the SPF for example, internal consulting and external consulting with partners ensures the systematic use of existing expertise and exchange of knowledge across disciplinary borders in the spirit of a learning organization. The consulting service also fosters the ongoing training of researchers in the roles of consultants and customers.

\section{Developing the workforce}

A successful integrative research enterprise not only depends on a carefully designed research agenda that responds to clinical and societal needs but also on the human resources necessary to perform the work [89]. Every research institution therefore has to engage in the continuous recruitment, education, training and career building of its workforce in a suitable organizational environment.

Human functioning and rehabilitation research is inherently multidisciplinary, interdisciplinary, or transdisciplinary [90-92] and is conducted by researchers originally trained in a wide range of scientific disciplines $[5,8]$. For a research institution developing its core competence from the comprehensive perspective, the development of the work force is thus particularly challenging.

\section{Recruitment}

There is a wide range of possibilities to recruit researchers from different scientific disciplines. They include the well known advertisements in scientific and public journals, internet postings and mailings to schools and institutions.

In addition, a promising recruitment strategy is to attract talented students through human functioning and rehabilitation researchers who are involved in educational programs of related disciplines. This provides the opportunity to identify and attract students who are both excellent in their discipline of origin and interested in looking beyond disciplinary boundaries at an early stage of their career. Considering the example of the SPF, researchers are involved as teachers in carefully selected BC and MS programs of partner institutions [11].

\section{Education and training}

A research institution from the comprehensive perspective should also be able to 'build' its own workforce by offering appropriate transdisciplinary education and training. In the case of the SPF for example, researchers are provided with the possibility to enroll in certificate, Master and $\mathrm{PhD}$ programs at the SPF in collaboration with partner universities [11]. The objective is that all researchers are at least educated in a certificate program in human functioning and rehabilitation research. This program is meant to ensure that all researchers internalize a transdisciplinary research approach, i.e., develop a common understanding of human functioning and rehabilitation research and adopt a common language based on WHO's ICF.

In such a certificate program, all researchers may over time act in the roles of both students and teachers. In a first phase, the researchers may be students in an unfamiliar area and teachers in an area close to their original expertise. In a second phase, they should be able to teach in a human functioning and rehabilitation research domain [8] reaching beyond their original discipline. Ultimately, researchers should be able to teach across a wide range of human functioning and rehabilitation research domains and account for respective interdependencies.

\section{Career building}

In modern society there is an increasing competition for talent. Therefore, one of the main challenges any research institution has to face is to retain trained researchers. One approach to remain attractive for researchers is to offer tailored career tracks for $\mathrm{PhD}$ scientists as well as professional scientists supported by appropriate funding mechanisms $[89,93]$.

The backbone of any research institution is made up by the scientists who pursue careers as principal investigators. To provide researchers with an attractive career perspective, integrative research institutions should offer a structured and competitive principal investigator career track. Scientists on this track may sequentially apply for a $\mathrm{PhD}$ program, a post-doctoral fellowship and a first time investigatorship. Finally, they may be appointed as senior investigators. In accordance with their career level, researchers on the principal investigator track keep academic appointments at partner universities either in the broad area of the health, human functioning or rehabilitation sciences or, alternatively, their primary discipline. This guarantees their eligibility for academic advancement. 


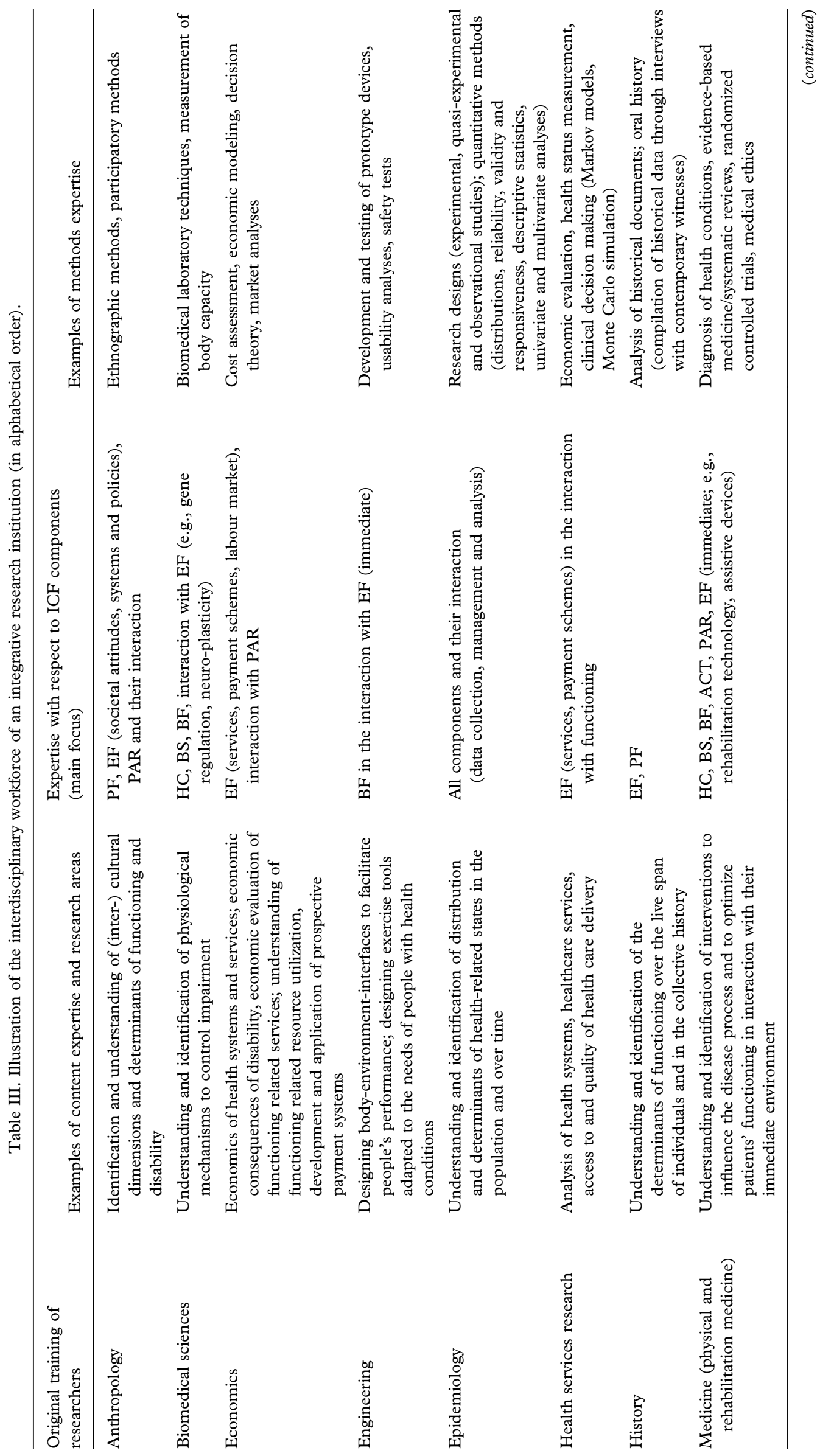


$\frac{c}{0}$
0
$\frac{0}{1}$
0
0
0
0
0
0

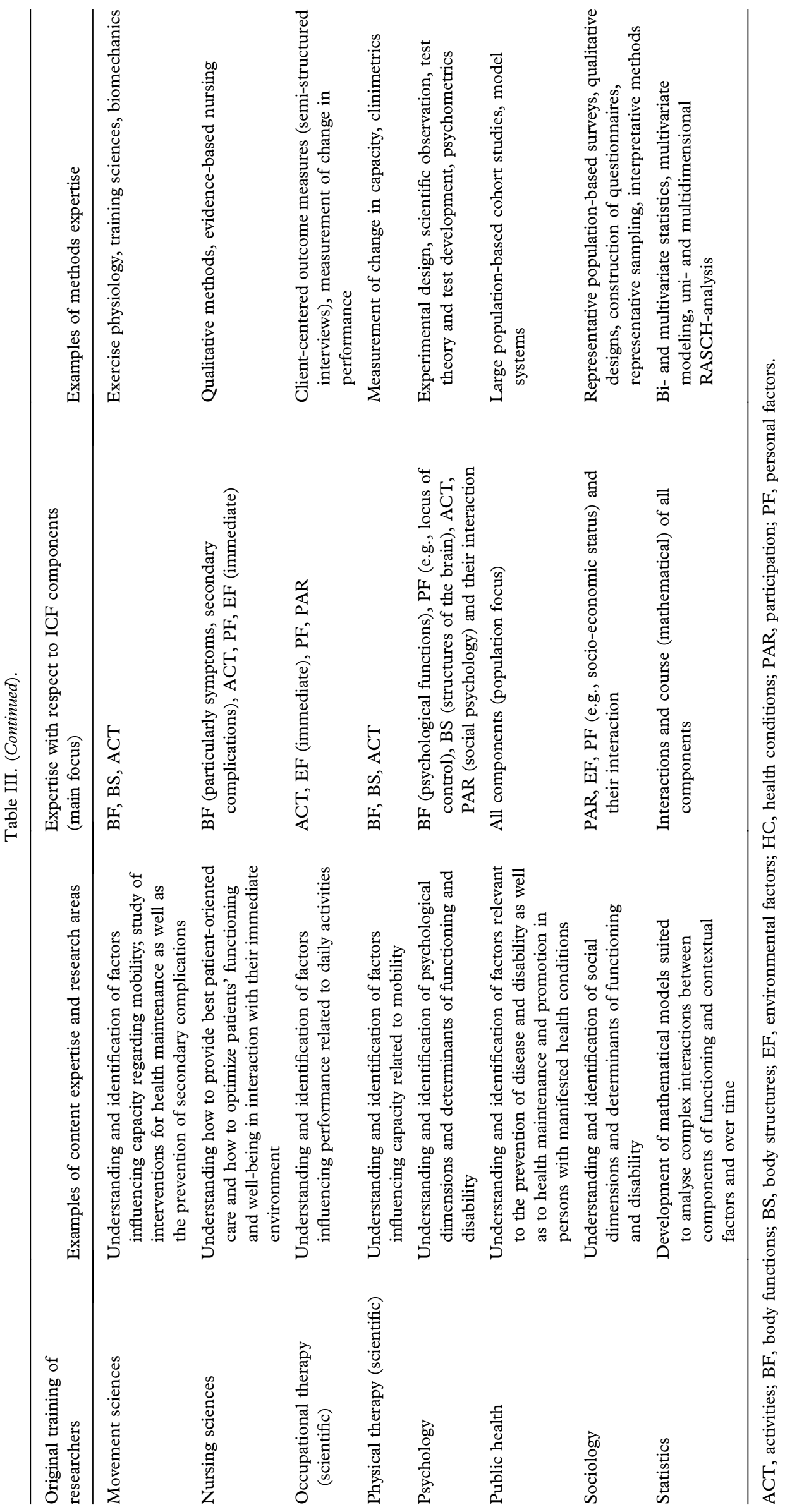


A most important element of career development is mentoring. SPF, for example, encourages all its scientists on its investigator track to work with mentors not only within but also outside the institution. To strengthen the mentoring process, SPF scientists on the principal investigator track can apply for guest-professorships at the SPF for their external mentors.

Besides scientists who pursue careers as principal investigators, a research institution also relies on project scientists and professional scientists. Project scientists provide the necessary balance of the workforce with respect to experience and proper execution versus innovation. They work in research projects at different levels such as assistant, junior or senior researcher but without pursuing academic advancement. Considering the example of the SPF, scientists on the principle investigator track may at any stage of their career switch to the project scientist career track. This mechanism ensures that the investment made in scientists on the investigator track is retained.

Well trained professional scientists are the key to linking research to the clinical, community and administrative perspectives [93]. The professional scientist track is an attractive option for a wide range of professionals working either in clinical settings, communities or administrations. SPF therefore offers a training fellowship for professionals including the enrolment in the mentioned certificate program in human functioning and rehabilitation research. Upon return to the clinical, community or administrative settings SPF offers mentoring and joint research programs.

Last but not least, a research institution engaging in the comprehensive study of functioning and disability should also make considerable efforts to recruit, train and retain researchers with an experience of disability of their own in relation to a health condition [94]. The SPF, for example, is committed to recruit and train researchers with SCI.

\section{Integration in the academic and research landscape}

\section{Collaborations}

Collaboration is not only essential for the recruitment and retaining of researchers but also a conditio sine qua non for the development of research programs in distinct scientific fields which are rather complementary than core competencies of an institution. Collaborations are also indispensable to participation in applications for national and international multi-centre grants.

An integrative research institution that develops its core competence from the comprehensive perspec- tive is uniquely positioned to integrate researchers from a wide range of disciplines across university faculties and units, and to develop a research agenda around the common theme of human functioning and rehabilitation.

At the university level, the SPF, for example, thus aims to participate in an interdisciplinary research centre for human functioning and rehabilitation [12]. At the national level, the SPF is considering the participation in or initiation of a collaboration network for human functioning and rehabilitation involving a wide range of stakeholders including associations of people living with SCI and research organizations, service providers and payers [12]. At the international level, the SPF participates in WHO's international collaboration network for the development of standards for the assessment of functioning and disability in practice, research and statistics led by the ICF research branch of the WHO Family of International Classifications (FIC) Germany (DIMDI) at the Ludwig-Maximilian University Munich.

The SPF's success will be also mirrored through an ongoing development of fruitful collaborations with all types of academic and stakeholder organizations.

\section{Developing funding channels}

Currently, funding for research from the comprehensive perspective is virtually unavailable in many countries. Most funding programs clearly focus on a partial perspective, most commonly the biomedical perspective, or on the perspective of a specific discipline [10]. Also, programs which foster interdisciplinary research often have specific aims which may not reflect the research agenda of integrative researchers [10].

Therefore, new funding channels and mechanism must be found. The SPF is, for example, developing suggestions regarding original funding topics and suitable funding mechanisms to gain the interest of funding agencies. To overcome the currently fractioned grant applications by related disciplines and institutions, the SPF aims to develop the mentioned collaborations for successful applications regarding larger funding programs on the national and international level.

\section{Concluding remarks}

Research institutes with a core competence in human functioning and rehabilitation research from the comprehensive perspective are urgently needed to integrate and translate the scientific advances into benefits for individual people affected by health conditions like SCI as well as for society as a whole 
[95]. Institutions like the SPF can serve as a catalyst for research which crosses the boundaries of the natural sciences and engineering research, the human and behavioral sciences as well as the social sciences $[5,8,11,12]$.

A research centre like the SPF with a well developed infrastructure including research personnel, equipment, space, and support staff can also serve as center of excellence and node for research and stakeholder collaborations. The success of the SPF can be monitored and evaluated particularly with regard to the umbrella goals. More concretely, it may become manifest through an increasing number of excellent grants and publications in the above depicted areas, the development of innovative research designs and methodological approaches to study functioning, the academic advancement of the SPF's principal investigators, and more and more fruitful collaborations with academic and stakeholder organizations. The ideas and approaches described in this paper may serve as an example for creating integrative research institutions dedicated to human functioning and rehabilitation research from the comprehensive perspective.

\section{Acknowledgements}

We thank the following researchers from Swiss Paraplegic Research for their suggestions and comments: Christine Boldt, Franziska Egli, Dr Inge Eriks-Hoogland, Angela Frotzler, Felix Gradinger, Dr Ursula Graumann, Dr Oliver Hausmann, Roger Hilfiker, Gabi Müller, Alexandra Rauch, Dr Stefan van Drongelen and Inge-Marie Velstra. Important ideas presented here also resulted from discussions with Drs Michael Baumberger and Franz Michel from the Swiss Paraplegic Clinical Centre as well as with John Leen from Orthotec. Finally, we thank Susanne Stucki for her continuous support as well as Andrew Pennycott and Gisela Immich for their help with the preparation of the manuscript.

\section{References}

1. Grimby G, Melvin J, Stucki G. The international classification of functioning, disability and health: A unifying model for the conceptualization, organization and development of human functioning and rehabilitation research. Foreword. J Rehabil Med 2007;39(4):277-278.

2. WHO. 58th World Health Assembly. Resolution R114. Disability, including prevention, management and rehabilitation. Adopted May 2005, Geneva.

3. Biering-Sørensen F, Scheuringer M, Baumberger M, Charlifue SW, Post MWM, Montero F, Kostanjsek N, Stucki G. Developing core sets for persons with spinal cord injury based on the international classification of functioning, disability and health as a way to specify functioning. Spinal Cord 2006;44(9):541-546.
4. Kennedy P, Lude P, Taylor N. Quality of life, social participation, appraisals and coping post spinal cord injury: A review of four community samples. Spinal Cord 2006; 44:95- 105 .

5. Stucki G, Grimby G. Organizing human functioning and rehabilitation research into distinct scientific fields. Part I: Developing a comprehensive structure from the cell to society. J Rehab Med 2007;39(4):293-298.

6. WHO. International Classification of Functioning, Disability and Health (ICF). Geneva: WHO Publications; 2001.

7. Stucki G. International Classification of Functioning, Disability, and Health (ICF): A promising framework and classification for rehabilitation medicine. Am J Phys Med Rehabil 2005;84(10):733-740.

8. Stucki G, Reinhardt JD, Grimby G. Organizing human functioning and rehabilitation research into distinct scientific fields. Part II: Conceptual descriptions and domains for research. J Rehab Med 2007;39(4):299-307.

9. Wang PP, Badley EM, Gignac M. Exploring the role of contextual factors in disability models. Disabil Rehabil 2006;28(2):135-140.

10. Frontera WR, Fuhrer MJ, Jette AM, Chan L, Cooper RA, Duncan PW, Kemp JD, Ottenbacher KJ, Peckham PH, Roth EJ, Tate DG. Rehabilitation medicine summit: building research capacity. Am J Phys Med Rehabil 2005; 84(12):913-917.

11. Stucki G. Developing human functioning and rehabilitation research. Part I: Academic training programs. J Rehabil Med 2007;39(4):323-333.

12. Stucki G, Celio M. Developing human functioning and rehabilitation research from the comprehensive perspective. Part II: Interdisciplinary university centers and national and regional collaboration networks. J Rehabil Med 2007;39(4): 334-342.

13. Prahalad CK, Hamel G. The core competence of the cooperation. Harvard Bus Rev 1990;68(3):79-93.

14. Cahil SE. Towards a sociology of the person. Sociological Theory 1998;16(2):131-148.

15. Dijkers $M$. Measuring quality of life: methodological issues. Am J Phys Med Rehabil 1999;78(3):286-300.

16. Post M, Noreau L. Quality of Life after spinal cord injury. J Neurol Phys Ther 2005;29(3):139- 146.

17. Berkman LF, Glass T, Brisette I, Seeman T. From social integration to health: Durkheim in the new millennium. Soc Sci Med 2000;51(6):843-857.

18. Lindström M, Hanson BS, Östergren P-O. Socioeconomic differences in leisure-time physical activity: The role of social participation and social capital in shaping health related behaviour. Soc Sci Med 2001;52(3):441-451.

19. Dalgard OS, Håheim LL. Psychological risk factors and mortality: A prospective study with special focus on social support, social participation, and locus of control in Norway. J Epidemiol Community Health 1998;52:476481.

20. Singh-Manoux A, Marmot M. Role of socialization in explaining social inequalities in health. Soc Sci Med 2005; 60(9):2129-2133.

21. Siegrist J. Social reciprocity and health: New scientific evidence and policy implications. Psychoneuroendocrinology 2005;30(10):1033-1038.

22. United Nations (UN): General Assembly 13.12.2006. Convention on the Rights of Persons with Disabilities. Available through URL: www.un.org/esa/socdev/enable/rights/convtexte. htm

23. Stucki G, Cieza A, Melvin J. The international classification of functioning, disability and health (ICF): A unifying model for a conceptual description of the rehabilitation strategy. J Rehabil Med 2007;39(4):279-285. 
24. Whiteneck GG, Charlifue SW, Gerhart KA, Oversholser JD, Richardson GN. Quantifying handicap: a new measure of long-term rehabilitation outcomes. Arch Phys Med Rehabil 1992;73(6):519-526.

25. Dijkers MPJM. Community integration: conceptual issues and measurement approaches in rehabilitation research. Top Spinal Cord Injury Rehabil 1998;4(1, I):1 - 15.

26. WHO. Current and future long-term care needs. An analysis based on the 1990 WHO study the global burden of disease and the international classification of functioning, disability and health. WHO; 2002. Available at URL: www.who.int/ chronic_conditions/ltc_needs.pdf

27. Boschen KA, Gargaro J, Tonack MI. Community integration and quality of life comparisons among spinal cord injured, support provider and comparative samples. Top Spinal Cord Inj Rehabil 2005;10(4):116-134.

28. Dijkers MPJM. Correlates of life satisfaction among persons with spinal cord injury. Arch Phys Med Rehabil 1999; 80(8):867-876

29. Noreau L, Fougeyrollas P, Post M, Asano M. Participation after spinal cord injury: The evolution of conceptualization and measurement. J Neurol Phys Ther 2005;29(3):147-156.

30. Post MWM, de Witte LP, van Asbek FWA, van Dijk AJ, Schrijvers AJP. Predictors of health status and life satisfaction in spinal cord injury. Arch Phys Med Rehabil 1998; $79(4): 395-401$.

31. Spencer Hansen N, Forchheimer M, Tate DG, Luera G. Relationships among community reintegration, coping strategies, and life satisfaction in a sample of persons with spinal cord injury. Top Spinal Cord Inj Rehabil 1998;4(1):56-72.

32. Whiteneck GG, Meade MA, Dijkers M, Tate DG, Bushnik T, Forchheimer MB. Environmental factors and their role in participation and life satisfaction after spinal cord injury. Arch Phys Med Rehabil 2004;85(11):1793-1803.

33. Krause JS. Skin sores after spinal cord injury: relationship to life adjustment. Spinal Cord 1998;36(1):51-56.

34. Dijkers MPJM, Yavuzer G, Ergin S, Weitzenkamp D, Whiteneck GG. A tale of two countries: Environmental impacts on social participation after spinal cord injury. Spinal Cord 2002;40(7):351-362.

35. Conroy L, McKenna K. Vocational outcome following spinal cord injury. Spinal Cord 1999;37(9):624-633.

36. Valtonen K, Karlsson AK, Alaranta H, Viikari-Juntura E. Work Participation among persons with traumatic spinal cord injury and meningomyelocele. J Rehabil Med 2006; 38(3):192-200.

37. Boschen KA, Tonack M, Gargaro J. Long-term adjustment and community reintegration following spinal cord injury. Int J Rehabil Res 2003;26(3):157-164.

38. Noreau L, Fougeyrollas P. Long-term consequences of spinal cord injury on social participation: the occurrence of handicap situations. Disabil Rehabil 2000;22(4):170 - 180.

39. Noreau L, Fougeyrollas P, Boschen KA. The perceived influence of the environment on social participation among individuals with spinal cord injury. Top Spinal Inj Rehabil 2002;7(3):56-72.

40. Chaves ES, Boninger ML, Cooper R, Fitzgerald SG, Gray $\mathrm{DB}$, Cooper RA. Assessing the influence of wheelchair technology on perception of participation in spinal cord injury. Arch Phys Med Rehabil 2004;85(11):1854-1858.

41. Larrson Lund M, Nordlund A, Nygard L, Lexell J, Bernspang B. Perceptions of participation and predictors of perceived problems with participation in persons with spinal cord injury. J Rehabil Med 2005;37(1):3-8.

42. Keysor JJ, Jette AM, Coster W, Bettger JP, Haley SM Association of environmental factors with levels of home and community participation in an adult rehabilitation cohort. Arch Phys Med Rehabil 2006;87:1566-1575.
43. Coleridge P. Disabled people and 'employment' in the majority world: policies and realities. In: Roulstone A, Barnes C, editors. Working futures? Disabled people, policy and social inclusion. Bristol: The Policy Press, 2005. pp 175-190.

44. Ehde DM, Jensen MP, Engel JM, Turner JA, Hoffman AJ, Cardenas DD. Chronic pain secondary to disability: A review. Clin J Pain 2003;19(1):3-17.

45. Ewert T, Fuessel M, Cieza A, Andersen C, Chatterji S, Kostanjsek N, Stucki G. Identification of the most common patient problems in patients with chronic conditions using the ICF checklist. J Rehabil Med 2004;44(Suppl.): $22-29$.

46. Ancoli-Israel S. The impact and prevalence of chronic insomnia and other sleep disturbances associated with chronic illness. Am J Manag Care 2006;12(8 Suppl.):S221 229.

47. Cardenas DD, Hoffman JM, Kirshblum S, McKinley W. Etiology and incidence of rehospitalization after traumatic spinal cord injury. Arch Phys Med Rehabil 2004;85(11): $1757-1763$.

48. Charlifue S, Lammertse DP, Adkins RH. Aging with spinal cord injury: Changes in selected health indices and life satisfaction. Arch Phys Med Rehabil 2004;85(11):18481853.

49. Sköld C, Levi R, Seiger A. Spasticity after traumatic spinal cord injury: Nature, severity and location. Arch Phys Med 1999;80(12):1548- 1557.

50. Cardenas DD, Jensen MP. Treatments of chronic pain in persons with spinal cord injury: A survey study. J Spinal Cord Med 2006;29:109-117.

51. Karlsson AK. Autonomic dysfunction in spinal cord injury: Clinical presentation of symptoms and signs. Prog Brain Res 2006; 152:1-8.

52. Benevento BT, Sipski ML. Neurogenic bladder, neurogenic bowel, and sexual dysfunction in people with spinal cord injury. Phys Ther 2002;82(6):601-612.

53. DeForge D, Blackmer J, Mohrer D, Garritty C, Cronin V, Yazdi F, Barrowman N, Mamaladze V, Zhang L, Sampson M. Sexuality and reproductive health following spinal cord injury. Summary. Evid Rep Technol Assess 2004;(109):1-8.

54. Rabchevsky AG. Segmental organization of spinal reflexes mediating autonomic dysreflexia after spinal cord injury. Prog Brain Res 2006;152:265-274.

55. Biering-Sørensen F. Urinary tract infections in individuals with spinal cord lesion. Curr Opin Urol 2002;12(1):45-49.

56. Winslow C, Rozovsky J. Effect of spinal cord injury on the respiratory system. Am J Phys Med Rehabil 2003;82(10): $803-814$.

57. Krassioukov A, Claydon VE. The clinical problems in cardiovascular control following spinal cord injury: An overview. Prog Brain Res 2006;152:223-229.

58. Weaver FM, Smith B, Evans CT, Kurichi JE, Patel N, Kapur VK, Burns SP. Outcomes of outpatient visits for acute respiratory illness in veterans with spinal cord injuries and disorders. Am J Phys Med Rehabil 2006;85(9): $718-726$.

59. Claydon VE, Steeves JD, Krassoukov A. Orthostatic hypotension following spinal cord injury: Understanding clinical pathophysiology. Spinal Cord 2006;44(6):341-351.

60. Bauman WA, Spungen AM. Metabolic changes in persons after spinal cord injury. Phys Med Rehabil Clin N Am 2000;11(1):109-140.

61. Jiang S-D, Dai L-Y, Jiang L-S. Osteoporosis after spinal cord injury. Osteoporos Int 2006;17(2):180-192.

62. Eser P, Frotzler A, Zehnder Y, Schiessl H, Denoth J. Assessment of anthropometric, systemic, and lifestyle factors influencing bone status in the legs of spinal cord injured individuals. Osteoporos Int 2005;16(1):26-34. 
63. Lee MY, Myers J, Hayes A, Madan S, Froelicher VF, Perkash I, Kiratli BJ. C-reactive protein, metabolioc syndrome, and insulin resistance in individuals with spinal cord injury. J Spinal Cord Med 2005;28(1):20-25.

64. van Drongelen S, de Groot S, Veeger HEJ, Angenot ELD, Dallmeijer AJ, Post MWM, van der Woude LHV. Upper extremity musculoskeletal pain during and after rehabilitation in wheelchair-using persons with a spinal cord injury Spinal Cord 2006;44(3):152-159.

65. Lindström B, Eriksson M. Salutogenesis. J Epidemiol Com Health 2005;59(6):440-442.

66. Blair SN, Church TS. The fitness, obesity and health equation. Is physical activity the common denominator? JAMA 2004;292(10):1232-1234.

67. Giles-Corti B. People or places: What should be the target? J Sci Med Sport 2006;9(5):357-366.

68. Lollar DJ, Crews JE. Redefining the role of public health in disability. Annu Rev Public Health 2003;24:195-208.

69. DeLisa JA. Answering the call: Improving the health and wellness of persons with disabilities. J Spinal Cord Med 2005;28(4):301-302.

70. Rimmer JH. Use of the ICF in identifying factors that impact participation in physical activity/rehabilitation among people with disabilities. Disabil Rehabil 2006;28(17):1087-1095.

71. Wyndaele $M$, Wyndaele JJ. Incidence, prevalence and epidemiology of spinal cord injury: What learns a worldwide literature survey? Spinal Cord 2006;44(9):523-529.

72. Krause JS, Crewe NM. Chronologic age, time since injury, and time of measurement: Effect on adjustment after spinal cord injury. Arch Phys Med Rehabil 1991;72(2):91-100.

73. Strauss DJ, DeVivo MJ, Paculdo DR, Shavelle RM. Trends in life expectancy after spinal cord injury. Arch Phys Med Rehabil 2006;87(8):1079-1085.

74. Garshick E, Kelley A, Cohen SA, Garrison A, Tun CG, Gagnon D, Brown R. A prospective assessment of mortality in chronic spinal cord injury. Spinal Cord 2005;43(7):408-416.

75. Krause JS, De Vivo MJ, Jackson AB. Health status, community integration and economic risk factors for mortality after spinal cord injury. Arch Phys Med Rehabil 2004;85(11): $1764-1773$.

76. Hicks AL, Martin KA, Ditor DS, Latimer AE, Craven C, Bugaresti J, McCartney N. Long-term exercise training in persons with spinal cord injury: Effects on strength, arm ergometry performance and psychological well-being. Spinal Cord 2003;41(1):34-43.

77. Nash MS. Exercise as a health-promoting activity following spinal cord injury. J Neurol Phys Ther 2005;29(2):87-103.

78. Haisma JA, van der Woude LHV, Stam HJ, Bergen MP, Sluis TAR, Bussmann JBJ. Physical capacity in wheelchair-dependent persons with a spinal cord injury: A critical review of the literature. Spinal Cord 2006;44(11):642-652.

79. Bucholz AC, McGillivray CF, Pencharz PB. Physical activity levels are low in free-living adults with chronic paraplegia. Obesity Res 2003;11(4):563-570.

80. Scelza WM, Kalpakjian CZ, Zemper ED, Tate DG. Perceived barriers to exercise in people with spinal cord injury. Am J Phys Med Rehabil 2005;84:576-583.
81. Rimmer JH, Schiller WJ. Future directions in exercise and recreation technology for people with spinal cord injury and other disabilities: Perspectives from the rehabilitation engineering research center on recreational technologies and exercise physiology for people with disabilities. Top Spinal Cord Inj Rehabil 2006;11(4):82-93.

82. van Houtte S, Vanlandewijck Y, Gosselink R. Respiratory muscle training in persons with spinal cord injury: A systematic review. Respiratory Med 2006;100(11):18861895.

83. Mueller G, Perret C, Spengler CM. Optimal intensity for respiratory muscle endurance training in patients with spinal cord injury. J Rehabil Med 2006;38(6):381-386.

84. Hausmann ON. Post-traumatic inflammation following spinal cord injury. Spinal Cord 2003;41(7):369-378.

85. Bronfenbrenner U. The ecology of human development. Cambridge, MA: Harvard University Press; 1979.

86. Fransen J, Stucki G, Twisk J, Chamot AM, Gerster JC, Langenegger T, Seitz M, Michel BA, and the members of the Swiss Clinical Quality Management in rheumatoid arthritis (SCQM). Effectiveness of a measurement feedback system on outcome in rheumatoid arthritis: A controlled clinical trial. Ann Rheum Dis 2003;62(7):624-629.

87. Behrman AL, Bowden MG, Nair PM. Neuroplasticity after spinal cord injury and training: An emerging paradigm shift in rehabilitation and walking recovery. Phys Ther 2006;86(10): $1406-1425$

88. Edgerton VR, Kim SJ, Ichiyama RM, Gerasimenko YP, Roy RR. Rehabilitative therapies after spinal cord injury. J Neurotrauma 2006;23(3-4):560 - 570.

89. Whyte J. Training and retention of rehabilitation researchers. Am J Phys Med Rehabil 2005;84:969-975.

90. Rosenfield PL. The potential of transdiciplinary research for sustaining and extending linkages between the health and social sciences. Soc Sci Med 1992;35(11):1343-1357.

91. Gebbie K, Rosenstock L, Hernandez LM, editors. Who will keep the public healthy? Educating public health professionals for the 21st century. Institute of Medicine, Washington DC: National Academic Press; 2003.

92. Stokols D, Harvey R, Gress J, Fuqua J, Phillips K. In vivo studies of transdisciplinary scientific collaboration. Lessons learned and implications for active living research. Am J Prev Med 2005;28(2S2):202-213.

93. Committee on National Needs for Biomedical and Behavioral Scientists et al. Addressing the nation's needs for biomedical and behavioral scientists. Washington DC: National Academy Press; 2000

94. Tregaskis C, Goodley D. Disability research by disabled and non-disabled people: Towards a relational methodology of research production. Int J Soc Res Methodol 2005;8(5):363374.

95. Fineberg HV. Science and medicine in the 21st century: Opportunities for rehabilitation medicine. Am J Phys Med Rehabil 2005;84(12):928-931. 